\section{When binary and continuous responses disagree}

In the observational TOCERRA study by Lauper $e t a l,{ }^{1}$ the authors showed that tocilizumab (TOC; either as monotherapy or combination therapy) had superior drug retention than tumour necrosis factor inhibitors (TNFi; as monotherapy or combination therapy), in patients with rheumatoid arthritis with prior exposure to at least one biologic disease-modifying antirheumatic drug (bDMARD). Yet, efficacy (measured by Clinical Disease Activity Index (CDAI) change over time) was the same! The authors offered the following astute explanations: (1) CDAI does not comprehensively assess drug efficacy; (2) different tolerance between TOC and TNFi groups; or (3) retention captures something that is not evaluated by CDAI. I would like to expand on these explanations, since this phenomenon has previously appeared in this journal.

When a patient starts any treatment, it is generally not continued if it is not effective. More so with expensive bDMARDs. In fact, many countries enforce bDMARD discontinuation unless response is demonstrated. Such a patient would typically stop contributing data to his treatment episode in the registry. The analyst cannot compare responses that she does not have. This essentially means that she is comparing response among responders of both treatment arms-unsurprising, then, that their responses were the same. Of course, not all non-responders discontinued treatment; we can see this from the data. Some evidence to support my point is that $24 \%$ of TOC monotherapy stopped due to inefficacy, far more than $14 \%$ in the TNFi combination group. ${ }^{1}$ How is this possible if efficacy were truly no different? (There should be no reason to believe that TNFi prescribers systematically under-recorded inefficacy as a reason for discontinuation.) A similar inconsistency was reported in the study by Ciurea $\mathrm{et} \mathrm{al}$, where current smoking did not (meaningfully) influence Bath Ankylosing Spondylitis Disease Activity Index (BASDAI) change over time, yet led to $45 \%$ reduced odds of BASDAI50 response, compared with never smokers. ${ }^{23}$

What is the solution? If the data are 'Missing Not at Random' (ie, missingness is determined by unmeasured values, as is likely the case here) then solutions can be complex. ${ }^{4}$ The LUNDEX method ${ }^{5}$ is one simple yet elegant option when binary outcome variables are used. But, in observational studies, binary variables are themselves problematic. ${ }^{2}$ Validity of binary responses depends on (1) no baseline differences between exposure groups (which was not the case in either studies ${ }^{12}$ ) and (2) how it is defined. Binary response variables can work with the LUNDEX if the denominator is defined as patients adhering to the drug, but not if it is all patients (ie, assuming that patients who discontinued were non-responders-a popular approach) (figure 1).

I would be interested to see the change in Disease Activity Score 28 joints (DAS28) over time, which was specified in methods but not reported, to see whether results were consistent with the greater TOC (monotherapy and combination therapy) response using binary derivatives of DAS28.

\section{Fengchen Ouyang $\odot$ \\ Retired, Xi'an, Shaanxi, China}

Correspondence to Fengchen Ouyang; oyfc18@gmail.com

Handling editor Josef S Smolen

Funding The authors have not declared a specific grant for this research from any funding agency in the public, commercial or not-for-profit sectors.

Competing interests None declared.

Patient consent Not required.

Provenance and peer review Not commissioned; externally peer reviewed. (c) Author(s) (or their employer(s)) 2020. No commercial re-use. See rights and permissions. Published by BMJ.
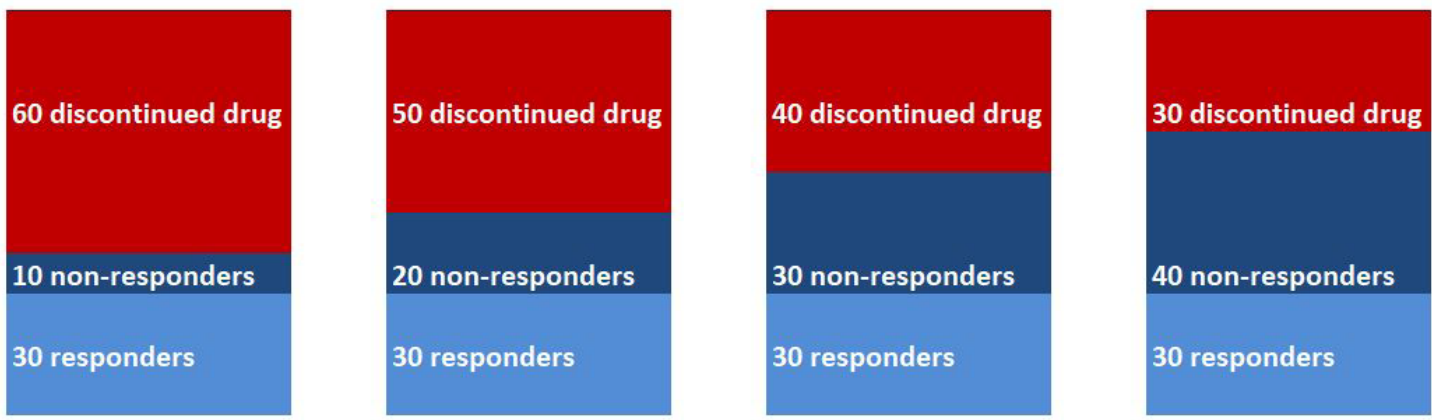

Adherers as denominator:

$$
\begin{aligned}
& \text { Response }=30 / 40=75 \% \\
& \text { Adherence }=40 \% \\
& \text { LUNDEX }=75 \% * 40 \%=30 \%
\end{aligned}
$$

$$
\begin{aligned}
& \text { Response }=30 / 50=60 \% \\
& \text { Adherence }=50 \% \\
& \text { LUNDEX }=60 \% * 50 \%=30 \%
\end{aligned}
$$

$$
\begin{aligned}
& \text { Response }=30 / 60=50 \% \\
& \text { Adherence }=60 \% \\
& \text { LUNDEX }=50 \% * 60 \%=30 \%
\end{aligned}
$$

Response $=30 / 70=43 \%$

Adherence $=70 \%$

LUNDEX $=43 \% * 70 \%=30 \%$

All patients as denominator:

$$
\begin{aligned}
& \text { Response }=30 \% \\
& \text { LUNDEX }=30 \% * 40 \%=12 \%
\end{aligned}
$$$$
\text { Response }=30 \%
$$

$$
\begin{aligned}
& \text { Response }=30 \% \\
& \text { LUNDEX }=30 \% * 60 \%=18 \%
\end{aligned}
$$

Response $=30 \%$

LUNDEX $=30 \% * 70 \%=\mathbf{2 1} \%$

Figure 1 Non-responders commonly, but variably, discontinue drug. The LUNDEX method multiplies the proportion of responders with proportion of adherers, at a fixed time point. It is an elegant solution to variable non-responder discontinuation when response is defined using adherers as the denominator, but not all patients. The latter is a common approach to define response in observational studies, but is not compatible with the LUNDEX. Readers should also note that patients who would have otherwise responded may discontinue for other reasons (eg, adverse events), which the LUNDEX does not account for. 


\section{Check for updates}

To cite Ouyang F. Ann Rheum Dis 2020;79:e38.

Received 21 December 2018

Accepted 22 December 2018

Published Online First 25 January 2019

\section{SLinked}

- http://dx.doi.org/10.1136/annrheumdis-2019-215019

Ann Rheum Dis 2020;79:e38. doi:10.1136/annrheumdis-2018-214968

ORCID iD

Fengchen Ouyang http://orcid.org/0000-0003-3522-4867

\section{REFERENCES}

1 Lauper K, Nordström DC, Pavelka K, et al. Comparative effectiveness of tocilizumab versus TNF inhibitors as monotherapy or in combination with conventional synthetic diseasemodifying antirheumatic drugs in patients with rheumatoid arthritis after the use of at least one biologic disease-modifying antirheumatic drug: analyses from the pan-European TOCERRA Register Collaboration. Ann Rheum Dis 2018;77:1276-82.

2 Ciurea A, Scherer A, Weber U, et al. Impaired response to treatment with tumour necrosis factor $\alpha$ inhibitors in smokers with axial spondyloarthritis. Ann Rheum Dis 2016;75:532-9.

3 Ciurea A, Finckh A. Smoking and spondyloarthritis. Joint Bone Spine 2013;80:234-5.

4 Sterne JA, White IR, Carlin JB, et al. Multiple imputation for missing data in epidemiologica and clinical research: potential and pitfalls. BMJ 2009;338:b2393.

5 Kristensen LE, Saxne T, Geborek P. The LUNDEX, a new index of drug efficacy in clinical practice: results of a five-year observational study of treatment with infliximab and etanercept among rheumatoid arthritis patients in southern Sweden. Arthritis Rheum 2006:54:600-6. 